Proceedings of XIX International Scientific Conference "New Technologies and Achievements in Metallurgy, Material Engineering, Production Engineering and Physics", Częstochowa, Poland, June 7-8, 2018

\title{
Transmission Properties of Two-Dimensional Chirped Phononic Crystal
}

\author{
S. Garus*, W. Sochacki And M. Bold \\ Institute of Mechanics and Fundamentals of Machinery Design, Częstochowa University of Technology, \\ J.H. Dąbrowskiego 73, 42-201 Częstochowa, Poland
}

\begin{abstract}
The mechanical wave transmission was investigated by a two-dimensional structure made of rods with a periodic arrangement - as the base structure. Compared structures had the same network constant in the direction perpendicular to the propagation of the acoustic wave, while the distances of subsequent layers of phononic crystal increased by a certain factor $k$. Depending on parameter $k$, chirped phononic crystal transmission properties were tested. The numerical analysis uses the finite difference time domain algorithm. The discrete Fourier transform allowed to determine the frequency characteristics of the tested systems. In order to verify numerical data, the experimental data was analyzed.
\end{abstract}

DOI: 10.12693/APhysPolA.135.153

PACS/topics: 43.60.Bf, 43.58.Kr, 43.20.Bi, 02.70.Bf

\section{Introduction}

The periodic arrangement of two or more materials is called a phononic crystal $(\mathrm{PhC})$. The diffraction and interference of mechanical waves propagating in phononic crystals affects the phononic phenomenon of a phononic band gap (PhBG), which means that waves with specific frequencies do not propagate in the structure. The determining of certain $\mathrm{PhC}$ properties is obtained by appropriate selection of the materials used that make up the composite structure and their geometrical parameters, such as shape or distribution [1]. We distinguish three types of $\mathrm{PhC}$ depending on the spatial distribution of materials that make up the structure: one (1D), two (2D) or three-dimensional (3D). The majority of research on the properties of phononic structures focuses on the band structure determination $[2-4]$.

These studies focus mainly on periodic structures, whereas for the aperiodic structures, the band structure cannot be determined. To determine the properties of 1D structures characterized by the lack of short-range ordering, algorithms such as transfer matrix method (TMM) and finite difference time domain (FDTD) are used [5]. The FDTD algorithm is used to study the propagation of mechanical waves in aperiodic $2 \mathrm{D}$ and $3 \mathrm{D}$ structures $[6,7]$.

Mechanical waves are used to extinguish the flame [8], and phononic structures can be used to direct and focus the beam. Phononic crystals can also be used as sensors, selective acoustic filters or noise suppressors $[9,10]$.

*corresponding author; e-mail: gari.sg@gmail.com
The FDTD method is one of the most efficient differential numerical techniques used in acoustics to analysed the mechanical wave propagation in aperiodic structures. The computation costs are high but calculations are very accurate.

Structures called chirped or graded materials are widely used due to their special properties allowing manipulation of the propagating wave. They are used for focusing, trapping, bending waves, opening of wide full band gaps, controlling reflection in the spatial dispersion beams [11].

\section{FDTD algorithm in $2 \mathrm{D}$}

The pressure field $P\left[\mathrm{~kg} /\left(\mathrm{m} \mathrm{s}^{2}\right)\right]$ and the phase velocity vector $\boldsymbol{v}[\mathrm{m} / \mathrm{s}]$ discretization in time and space lead to obtain an FDTD algorithm for acoustic wave propagation. The interdependence between $P$ and $\boldsymbol{v}$ is depicted by the first order acoustic equations, which are denoted as

$$
\begin{aligned}
& \frac{1}{\rho c^{2}} \frac{\partial P}{\partial t}=-\nabla \cdot \boldsymbol{v}, \\
& \rho \frac{\partial \boldsymbol{v}}{\partial t}=-\nabla P,
\end{aligned}
$$

where $\rho\left[\mathrm{kg} / \mathrm{m}^{3}\right]$ is material mass density and $c$ is the phase velocity of mechanical wave propagated.

Equations (1) and (2) expanded in terms of components for $2 \mathrm{D}$ case takes the form

$$
\left\{\begin{array}{l}
\frac{\partial v_{x}}{\partial t}=-\frac{1}{\rho} \frac{\partial P}{\partial x}, \\
\frac{\partial v_{y}}{\partial t}=-\frac{1}{\rho} \frac{\partial P}{\partial y},
\end{array}\right.
$$$$
\frac{\partial P}{\partial t}=-\rho c^{2}\left(\frac{\partial v_{x}}{\partial x}+\frac{\partial v_{y}}{\partial y}\right),
$$

Which, after converting derivatives into differential equations, gives the form of recursive equations for the point $(i, j)$ of the discretized two-dimensional space located at the time $(n)$ as 


$$
\begin{aligned}
& P^{n+1}(i, j)=P^{n}(i, j)-\rho(i, j)(c(i, j))^{2} \frac{\Delta t}{\Delta z} \\
& \times\left[v_{x}^{n+1 / 2}(i, j)-v_{x}^{n+1 / 2}(i-1, j)\right. \\
& \left.\quad+v_{y}^{n+1 / 2}(i, j)-v_{y}^{n+1 / 2}(i, j-1)\right], \\
& v_{x}^{n+1 / 2}(i, j)=v_{x}^{n-1 / 2}(i, j) \\
& -\frac{\Delta t}{\Delta z \rho(i, j)}\left[P^{n}(i+1, j)-P^{n}(i, j)\right], \\
& v_{y}^{n+1 / 2}(i, j)=v_{y}^{n-1 / 2}(i, j) \\
& -\frac{\Delta t}{\Delta z \rho(i, j)}\left[P^{n}(i, j+1)-P^{n}(i, j)\right] .
\end{aligned}
$$

Alternating calculations of Eqs. (5)-(7) allow to simulate the propagation of a mechanical wave in given materials.

The boundary conditions were perfect matched layer (PML), in consequence of which the propagating mechanical wave was extinguished and did not take its reflection towards the simulation area.

\section{Research}

The work analyzed the propagation of mechanical waves in the phononic structure using the FDTD algorithm. The structure shown in Fig. 1 was made of polypropylene rods with a diameter of $25 \mathrm{~mm}$ distributed for the base structure $(k=0)$ with a lattice constant $a_{y}$ equal to $40 \mathrm{~mm}$ which should expire the wave for frequencies around the $4143 \mathrm{~Hz}$. The following columns are distant from each other according to the dependence $a_{i}=a_{y}+i k$ for $k$ taking the following values: $\{0,0.5$, $1\} \mathrm{cm}$. The distance $d_{s}$ from the sound source to the tested structure was $30 \mathrm{~cm}$, and the distance from the structure to the analyzer was $d_{d}=10 \mathrm{~cm}$. The space was digitized with a step of $\Delta z=5 \mathrm{~mm}$. In order to stabilize the simulation, the time step $\Delta t$ is determined from the Courant condition, which for $2 \mathrm{D}$ simulation for maximum wave velocity in simulation is determined by the dependence

$$
\Delta t<\left[c_{\max } \sqrt{\frac{1}{(\Delta x)^{2}}+\frac{1}{(\Delta y)^{2}}}\right]^{-1} .
$$

In the simulation, the time step value was determined as $\Delta t=\Delta z /\left(2 c_{\max }\right)$ for the maximum propagation velocity $c_{\max }$ of the wave taken as $3000 \mathrm{~m} / \mathrm{s}$.

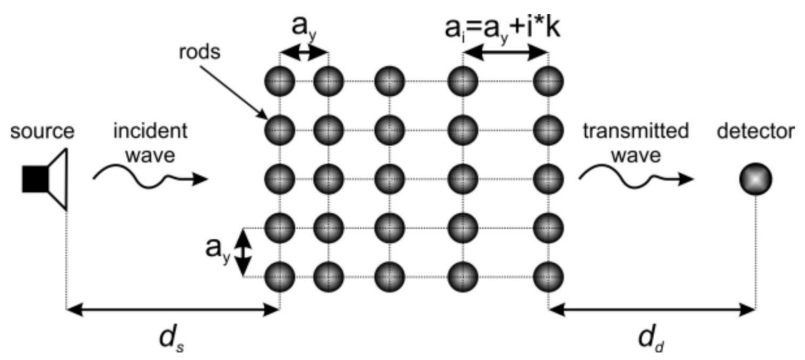

Fig. 1. Diagram of the measurement system with the analyzed structure.
TABLE I

Material parameters of the components [12, 13].

\begin{tabular}{l|c|c}
\hline \hline \multicolumn{1}{c|}{ Material } & $\begin{array}{c}\text { Mass density } \\
\rho\left[\mathrm{kg} / \mathrm{m}^{3}\right]\end{array}$ & $\begin{array}{c}\text { Velocity of sound } \\
v[\mathrm{~m} / \mathrm{s}]\end{array}$ \\
\hline $\mathrm{Zr}_{55} \mathrm{Cu}_{30} \mathrm{Ni}_{5} \mathrm{Al}_{10}$ & 6829 & 1633 \\
polypropylene & 900 & 1450 \\
air & 1.29 & 331.45
\end{tabular}

In order to suppress the wave in the simulation, 8 layers of PML were used around the studied area.

Table I summarizes the material parameters of the analyzed structure.

Amorphous alloys are an intensively studied group of materials, especially their magnetic properties [14-17] and the occurrence of the magnetocaloric effect are analyzed [18-21]. The study investigated the influence of material on wave propagation by converting rods made of polypropylene to an amorphous alloy $\mathrm{Zr}_{55} \mathrm{Cu}_{30} \mathrm{Ni}_{5} \mathrm{Al}_{10}$.

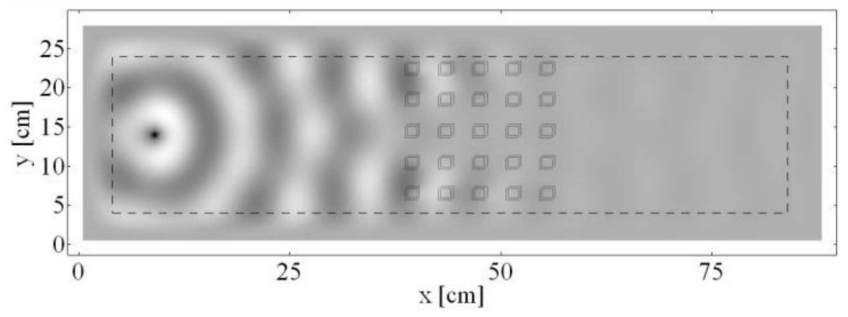

Fig. 2. Pressure distribution after 5,000 steps for a structure made of polypropylene for an incident wave frequency of $4143 \mathrm{~Hz}$ and $k=0$.
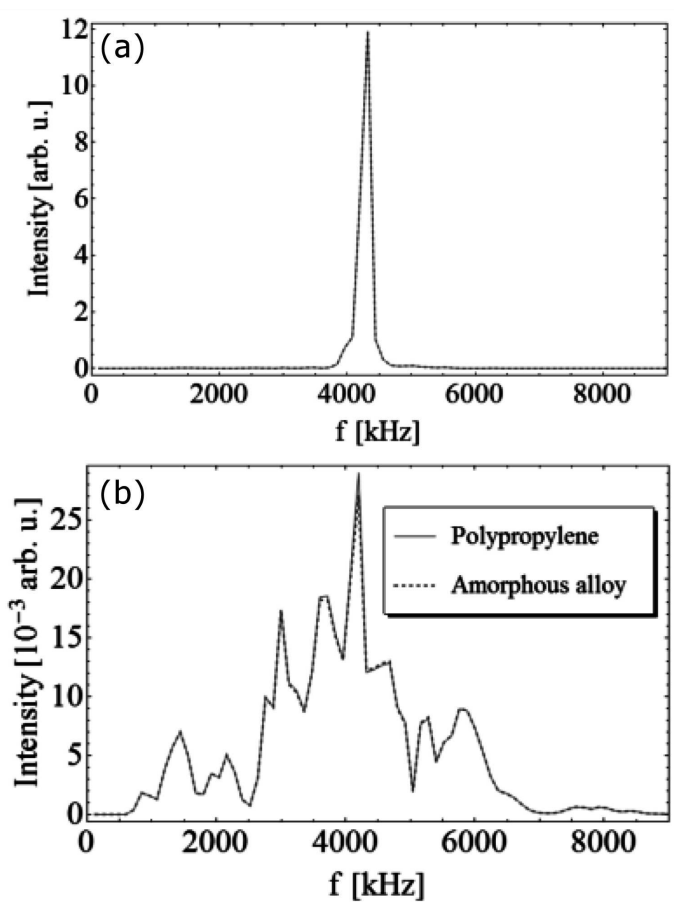

Fig. 3. Power spectrum for (a) incident and (b) transmitted wave for two different rods materials. 

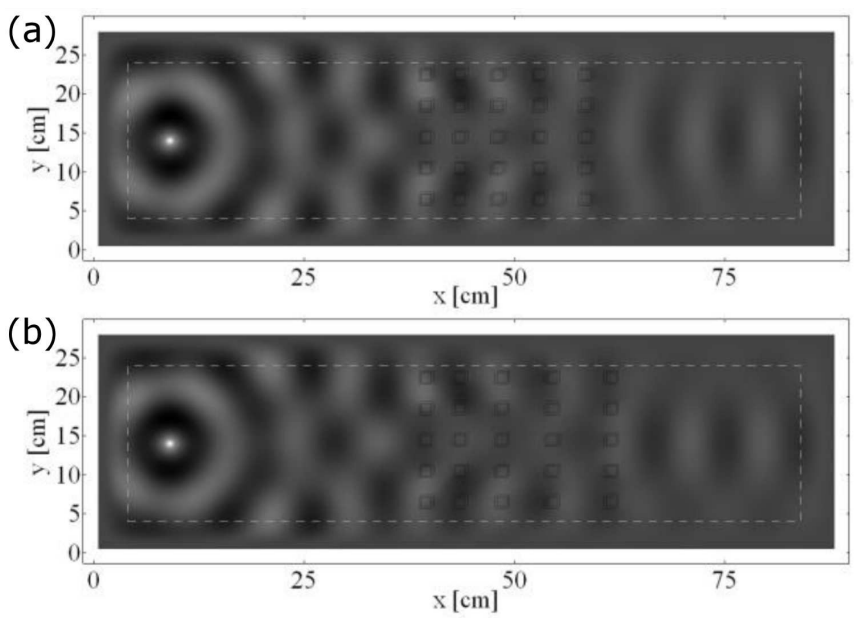

Fig. 4. Pressure distribution for (a) $k=5 \mathrm{~mm}$ and (b) $k=10 \mathrm{~mm}$.
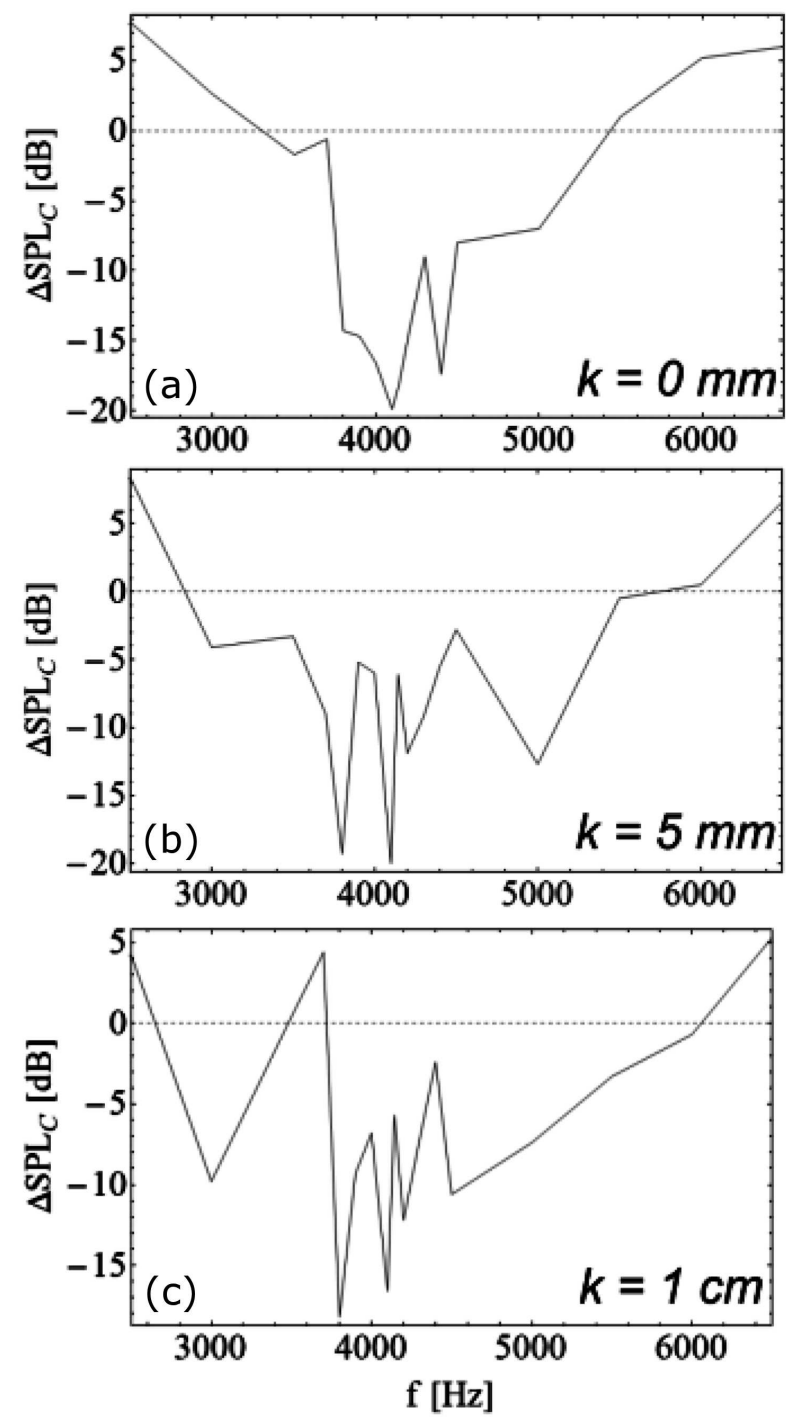

Fig. 5. Change in sound pressure level in relation to the measuring system without structure for (a) $k=$ $0 \mathrm{~mm}$, (b) $k=5 \mathrm{~mm}$ and (c) $k=10 \mathrm{~mm}$.
The results for 5000 simulation time steps for different materials are almost identical and are shown in Fig. 2. Inside the dashed line in Fig. 2 is the test area but outside the extinction of the wave occurs - in PML area. Figure 3 shows the signal power spectrum obtained on the basis of discrete Fourier transform pressure time series before (Fig. 3a) and after (Fig. 3b) of analyzed structure. One can notice a clear lack of material influence on the propagation of a mechanical wave in the phononic structure.

Figure 4 shows the pressure distribution for $k$ equal to $5 \mathrm{~mm}$ (Fig. 4a) and $10 \mathrm{~mm}$ (Fig. 4b) for $f=4143 \mathrm{~Hz}$. After the DFT was conducted, the power spectrum was determined, and on its basis the transmission parameters of the tested signal were determined. For $k$ equal to 0 , 0.5 , and $1 \mathrm{~cm}$ the transmission coefficient was $0.23 \%$, $39.4 \%$, and $31.8 \%$, respectively.

On the basis of Fig. 1, a measurement stand was built where the generated mechanical sinusoidal wave pulse was passing through the structures. Sound pressure level was measured using a Norsonic Nor140 detector. The measurement results are collected in Fig. 5.

\section{Conclusions}

The paper proposes a phononical structure for the acoustic wave range made of polypropylene rods with a spatial distribution where the center of bandgap is designated theoretically as $4143 \mathrm{~Hz}$. The simulation using the FDTD algorithm confirmed the existence of a bandgap for the base structure, and the change in the material of the rods did not affect the behavior of the mechanical wave propagation. Increase of the parameter $k$ influenced the increase of the transmission coefficient of the structure under examination.

The experiment confirmed the existence of a band gap near the frequency of $4100 \mathrm{~Hz}$. The reduction of the sound pressure level was on the order of $20 \mathrm{~dB}$ almost to the acoustic background level. For non-zero values of the parameter $k$, the band gap was shifted toward the lower frequencies. Such structures could be used in acoustic barriers.

\section{References}

[1] M.H. Lu, L. Feng, Y.F. Chen, Mater. Today 12, 34 (2009).

[2] Y. Liu, J.Y. Su, Y.L. Xu, X.C. Zhang, Ultrasonics 49, 276 (2009).

[3] J.O. Vasseur, B. Djafari-Rouhani, L. Dobrzynski, P.A. Deymier, J. Phys. Condens. Matter 9, 7327 (1997).

[4] L. Zhong, F. Wu, X. Zhang, H. Zhong, S. Zhong, Phys. Lett. A 339, 164 (2005).

[5] S. Garus, W. Sochacki, J. Appl. Math. Comput. Mech. 16, 17 (2017).

[6] D.M. Sullivan, Electromagnetic Simulation Using the FDTD Method, IEEE Press, New York 2000. 
[7] A. Taflove, Computational Electrodynamics: The Finite-Difference Time-Domain Method, Artech House, Norwood (MA) 1995.

[8] P. Niegodajew, K. Lukasiak, H. Radomiak, D. Musiał, M. Zajemska, A. Poskart, K. Gruszka, Combust. Flame 194, 245 (2018).

[9] I. Kriegel, F. Scotognella, Physica E 85, 34 (2017).

[10] S. Villa-Arango, R. Torres, P.A. Kyriacou, R. Lucklum, Measurement 102, 20 (2017).

[11] N. Jiménez, V. Romero-García, A. Cebrecos, R. Picó, V.J. Sánchez-Morcillo, L.M. Garcia-Raffi, AIP Adv. 6, 121605 (2016)

[12] S. Yang, W.D. Yu, N. Pan, Physica B Condens. Matter 406, 963 (2011).

[13] M. Fukuhara, X. Wang, A. Inoue, J. Non-Cryst. Solids 356, 1707 (2010).

[14] M.G. Nabialek, P. Pietrusiewicz, M.J. Dospial, M. Szota, K. Błoch, K. Gruszka, K. Oźga, S. Garus, J. Alloys Comp. 615, S51 (2015).
[15] K. Błoch, M. Nabiałek, Acta Phys. Pol. A 127, 413 (2015).

[16] S. Garus, M. Nabiałek, J. Garus, Acta Phys. Pol. A 126, 960 (2014).

[17] J. Garus, S. Garus, M. Nabiałek, M. Szota, Acta Phys. Pol. A 126, 954 (2014).

[18] P. Gebara, P. Pawlik, B. Michalski, J.J. Wysłocki, Acta Phys. Pol. A 127, 576 (2015).

[19] P. Gębara, P. Pawlik, J. Magn. Magn. Mater 442, 145 (2017).

[20] A. Jakubas, P. Gebara, S. Seme, A. Gnatowski, K. Chwastek, Acta Phys. Pol. A 131, 1289 (2017).

[21] P. Gębara, J. Marcin, I. Skorvanek, J. Electron. Mater. 46, 6518 (2017). 